\title{
Comparative Evaluation of Colour Stability Among Cad Cam and Resin Interim Restoration- an in Vitro Study
}

\author{
Nashwah Hinaz ${ }^{1}$, Ashok V², Kiran Kumar ${ }^{3}$ and Dhanraj Ganapathy ${ }^{4}$ \\ ${ }^{1}$ Saveetha Dental College and Hospitals Saveetha Institute of Medical \\ and Technical Sciences Saveetha University Chennai, India \\ ${ }^{2}$ Professor and Head (Admin), Department of Prosthodontics Saveetha Dental College and Hospitals \\ Saveetha Institute of Medical and Technical Sciences, Saveetha University Chennai, India \\ ${ }^{3}$ Senior Lecturer Department of Prosthodontics Saveetha Dental College and Hospitals \\ Saveetha Institute of Medical and Technical Sciences, Saveetha University Chennai, India \\ ${ }^{4}$ Professor and Head (Academics), Department of Prosthodontics Saveetha Dental College and Hospitals \\ Saveetha Institute of Medical and Technical Sciences, Saveetha University Chennai, India
}

\section{ABSTRACT}

The provisional restorations are used for an interim period in fixed prosthodontics. In a few situations, it can also be used as a long term provisional restoration. In the case of long term provisional restorations, the major concern is the aesthetics and function. In anterior tooth replacement, colour stability is the main criteria for selection of material. Colour stability can be affected by various reasons. The aim of the study is to evaluate the colour stability on CAD-CAM interim restoration and the conventional interim restoration. Eight samples each of heat cure provisional and CAD-CAM resin milled provisional are fabricated and tested in a toothbrush simulator for a period of 24hrs. The average period of abrasion is for 9 months. Pre-test and post-test measurement of its absorbance using spectrophotometer done. The results showed that CAD-CAM provisional restorations have better colour stability than conventional heat-cured provisional restorations even after 9 months. This can be due to less monomer residue, better mechanical properties. Colour stability is an important criterion when anterior restoration is concerned. Discolouration of the restoration can be due to various factors that may lead to patient dissatisfaction. The CAD-CAM provisional restorations can be a better choice as a long term provisional restoration in the aesthetic zone.

KEY WORDS: PROVISIONAL RESTORATIONS, CAD-CAM TEMPORIZATION, COLOUR STABILITY, AESTHETICS, TOOTHBRUSH SIMULATOR.

\section{ARTICLE INFORMATION}

*Corresponding Author: dhanrajmganapathy@yahoo.co.in Received 8th Aug 2020 Accepted after revision 26th Sep 2020 Print ISSN: 0974-6455 Online ISSN: 2321-4007 CODEN: BBRCBA

Thomson Reuters ISI Web of Science Clarivate Analytics USA and Crossref Indexed Journal

$$
\begin{gathered}
\text { Clarivate } \\
\text { Analytics }
\end{gathered}
$$




\section{INTRODUCTION}

In fixed prosthodontics, replacement of missing teeth is the primary aim of treating patients to regain aesthetics and function. The restoration done can be either toothsupported prosthesis or implant-supported prosthesis. In tooth-supported prosthesis evaluation of abutment teeth are at-most important for treatment success. An implantsupported prosthesis can be either immediate loading or delayed loading. In implant-supported prosthesis, the formation of gingival collar especially in the anterior region is important in the aesthetic point of view. In immediate loading of implants, permanent restorations either with metal-ceramic or all-ceramic will be challenging in the aesthetic area, due to unpredictability in the healing of soft tissue. In such situations, interim restoration is one of the choices.

There are various interim restorative materials available. Polymethyl methacrylate (PMMA) is one of the most commonly used denture base material(Sepúlveda-Navarro et al., 2011) (Goiato et al., 2013).The types of PMMA resin includes heat-cured resin, auto-polymerizing acrylic resin, light-cured resin, microwave processing resin, computer-aided design/computer-aided manufacturing (CAD/CAM) PMMA block resin(Tuna et al., 2013; Choi et al., 2018). The most commonly used PMMA resins are heat cured and CAD-CAM resin. Heat cured polymethylmethacrylate (PMMA) resin is the most widely used material for the construction of removable prostheses and for interim fixed restoration. The advantages include low cost, ease of manipulation, adequate physical and mechanical properties and disadvantages include poor colour stability and abrasion(Berger et al., 2006)(Berger et al., 2006; Palaskar, Mittal and Singh, 2013; Gungor, Gundogdu and Duymus, 2014).

CAD/CAM technology has multiple prosthetic applications including the fabrication of intra-coronal and extracoronal restorations, crowns, fixed partial dentures and more recently, the construction of complete denture and maxillofacial prostheses. CAD/CAM allows the use of novel materials with improved characteristics but it is crucial to understand and assess the mechanical properties of these newer materials(van Noort, 2012).With advancement in digital dentistry, PMMA based polymer blocks are replacing the conventional method of using acrylic resin for the fabrication of interim crowns(Alp, Murat and Yilmaz, 2019)

The aesthetic outcome is an important factor for anterior restorations. The colour stability should be adequate to the patient's expectation and satisfaction(Heydecke et al., 2003; Sahin et al., 2016). Hence it is essential to understand the colour stability of different materials in order to obtain the best treatment outcome for the patient. A Spectrophotometer is used to analyse the colour stability of different materials. It is a scientific standardized colorimetric equipment for matching and measuring colors that gives information about the reflectance curve as a function of wavelengths in the entire visible range and thus numerically specifies the perceived color of an object. CIELAB color coordinates system is a very useful mode that provides information about location of object color in a uniform 3-dimensional color space. It quantifies the color in terms of three coordinate values $L^{*}$, $a^{*}$ and $b^{*}$. Here $L^{*}$ represents brightness or lightness (value) and $\mathrm{a}^{*}$ and $\mathrm{b}^{*}$ serve as numeric correlates both for hue and chroma.(Hong et al., 2009).

Previously our department has published extensive research on various aspects of prosthetic dentistry ('Evaluation of Corrosive Behavior of Four Nickelchromium Alloys in Artificial Saliva by Cyclic Polarization Test:An in vitro Study', 2017; Ganapathy, Kannan and Venugopalan, 2017; Jain, 2017a, 2017b; Ranganathan, Ganapathy and Jain, 2017; Ariga et al., 2018; Gupta, Ariga and Deogade, 2018; Anbu et al., 2019; Ashok and Ganapathy, 2019; Duraisamy et al., 2019; Varghese, Ramesh and Veeraiyan, 2019), this vast research experience has inspired us to research about the colour stability of the heat polymerized resin interim restoration and CAD CAM milled interim restoration.

\section{MATERIAL AND METHODS}

A total of 16 samples are fabricated for the study. These samples are divided into two groups. Group 1 Heat polymerized resin interim restoration (Fig 1) Group 2 CAD-CAM milled resin interim restoration (Fig2) The samples are fabricated after virtual designing using the CAD software(3Shape- Trios). This technique is followed to have seven thicknesses and form. The virtual design is directly converted into CAD CAM Interim restoration by direct milling (I-Core, Germany). For heat polymerized resin interim restoration, the virtual design is milled with pattern resin and the pattern resin is converted into heat polymerized resin interim restoration. The pretest absorbance $\Delta \mathrm{E}$ values are measured using the spectrophotometer (VITA easyshade V) (fig 3A and 3B)

Figure 1: Heat cure interim samples

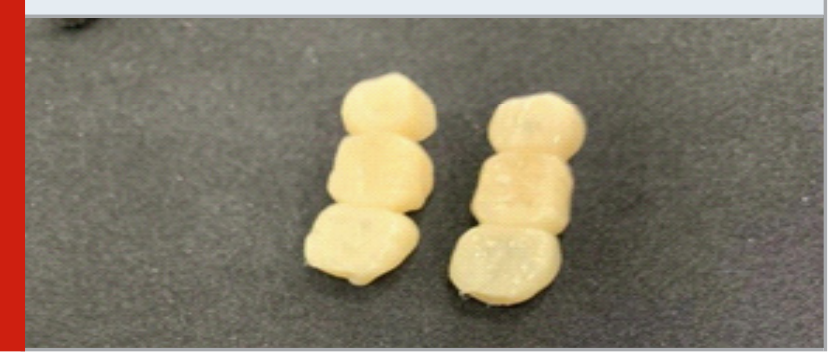

Figure 2: CAD-CAM interim samples

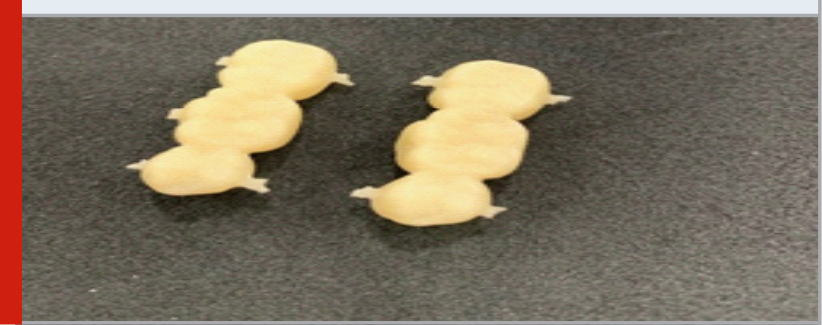


Figure 3. (A): Pre-test absorbance $\Delta \mathrm{E}$ value for heat- cured provisional

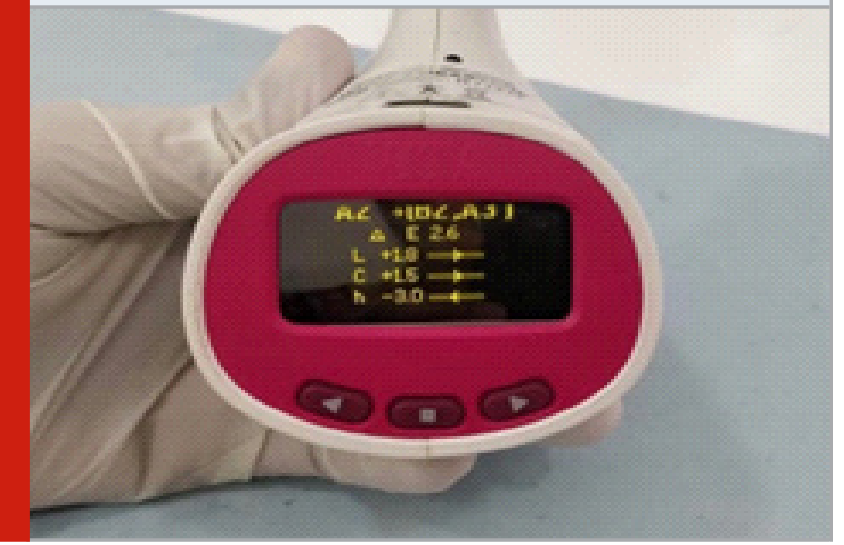

Figure 3 (B): Pre-test absorbance $\Delta \mathrm{E}$ value for $\mathrm{CAD}-\mathrm{CAM}$ provisional

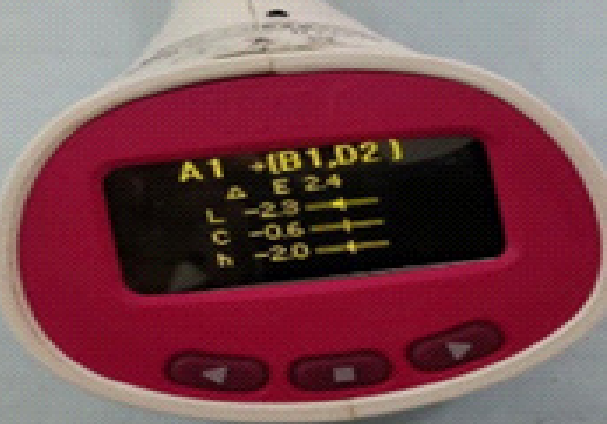

Figure 4: Toothbrush simulator with samples.

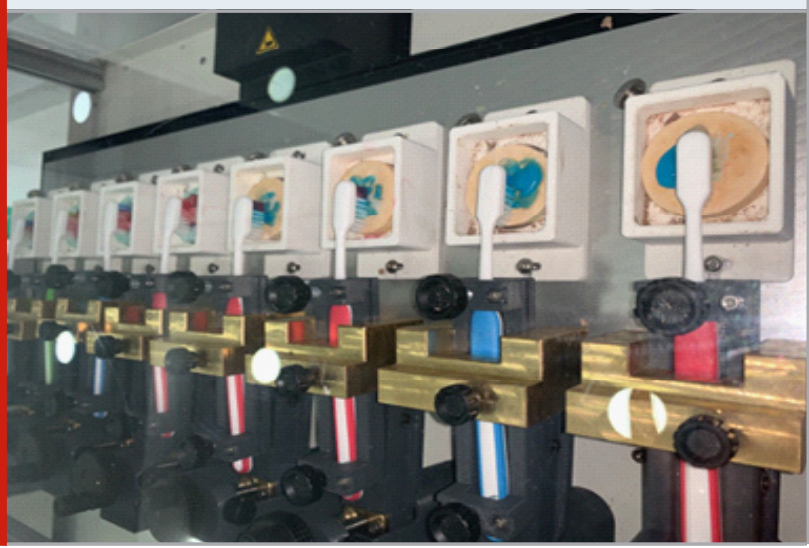

The samples are made to run in a toothbrush simulator for 24 hrs continuously with coloured toothpaste (Fig 4). Toothbrush simulator is a device used for the simulation of tooth-cleaning processes by commercially available toothbrushes. The toothbrushes used for the study are with medium graded bristles. The tooth brushing machine included eight holders for toothbrushes. Each toothbrush worked on 1 specimen. The holders for the toothbrushes are customized for the toothbrush handle to hold the toothbrush in place. The specimens are mounted with standardized key lock fixations. The bristles of the toothbrush are aligned without pressure perpendicularly contacting the specimen surface. After 24hrs, the specimens are retrieved from the tooth brush simulator and the posttest measurement of its absorbance are recorded using the spectrophotometer and $\Delta \mathrm{E}$ values measured. (Fig 5A and 5B)

Figure 5 (A): Post-test absorbance $\Delta \mathrm{E}$ value for Heat-cured provisional

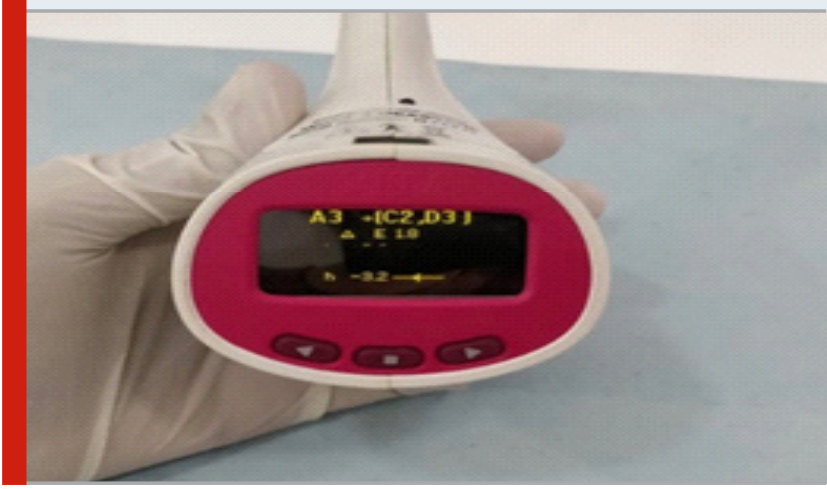

Figure 5 (B): Post-test absorbance $\Delta \mathrm{E}$ value for CAD-CAM provisional

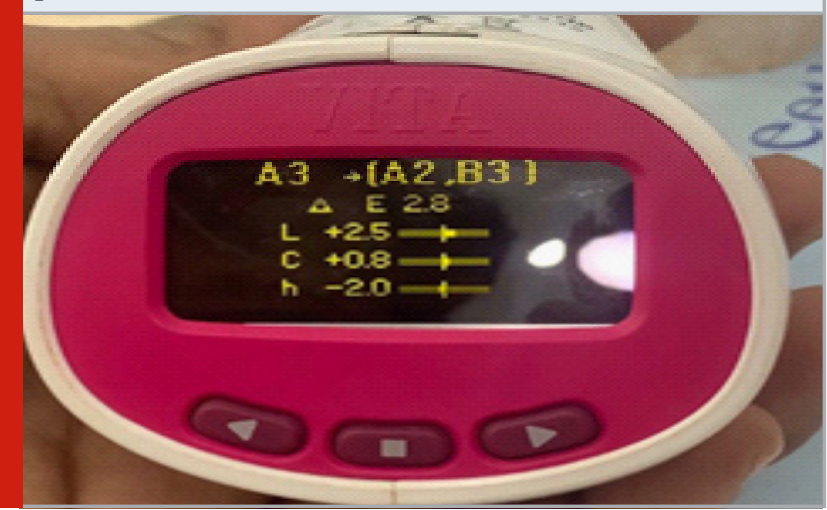

RESULTS

Conventional heat cure based PMMA interim restorations in the present study showed significantly higher colour change as compared to PMMA-based CAD/CAM interim restorations. Statistical analysis with one way anova test using SPSS software is done to obtain results. From (figure 6), it is seen that the average $\Delta \mathrm{E}$ value in heat cure provisional shows a large difference in each sample. Sample 2 and 6 had the highest difference with $\Delta \mathrm{E}$ values 3.7 and 3.4 followed by sample 7 with $\Delta \mathrm{E}$ value of 2.7 respectively. However the average $\Delta \mathrm{E}$ value in CAD-CAM provisional showed small differences in all 8 CAD-CAM samples with values ranging between 0.2- 0.7 as shown in (figure 7). Table 1 shows one way ANOVA test done which is statistically significant with $p<0.001$. This is due to increased wear resistance of CAD-CAM interim restoration and optimal condition during which polymerization of CAD/CAM materials takes place, 
therefore resulting in improved monomer-to-polymer conversion rate in addition to low polymerization shrinkages.

Figure 6: Bar chart showing the pre treatment, post treatment and $\Delta \mathrm{E}$ value values of heat cure provisional restorations in 8 samples. $\mathrm{X}$ axis represents the heat cure restoration samples and $\mathrm{Y}$ axis represents the mean value. Blue denotes pretreatment values, red denotes post treatment values and green denotes $\Delta \mathrm{E}$ value. Heat cure provisional samples show larger differences in $\Delta \mathrm{E}$ values One way ANOVA test is done and $\mathrm{p}<0.001$

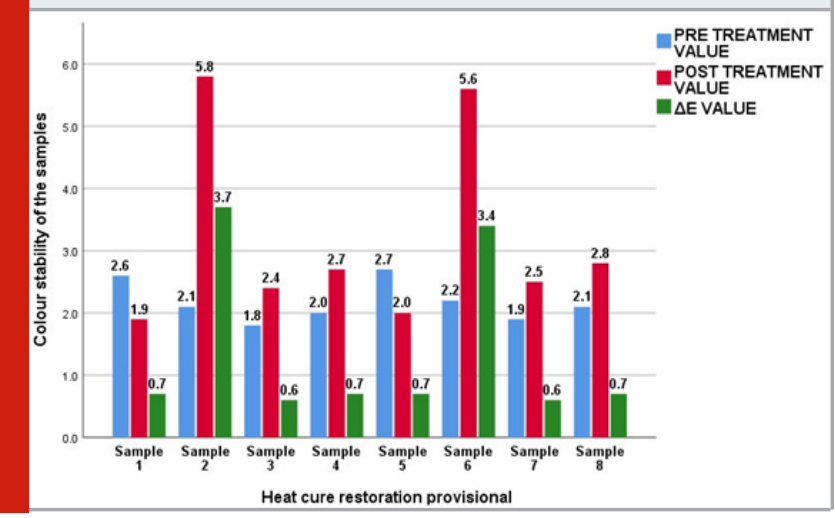

Figure 7: Bar chart showing the pre treatment, post treatment and $\triangle \mathrm{E}$ value values of $\mathrm{CAD}-\mathrm{CAM}$ provisional restorations in 8 samples. $\mathrm{X}$ axis represents the CADCAM restoration samples and $\mathrm{Y}$ axis represents the mean value. Blue denotes pretreatment values, red denotes post treatment values and green denotes $\Delta \mathrm{E}$ value. The $\mathrm{CAD}-\mathrm{CAM}$ sample shows a lesser difference in $\triangle \mathrm{E}$ value in each of the samples. One way ANOVA test is done and $\mathrm{p}<0.001$.

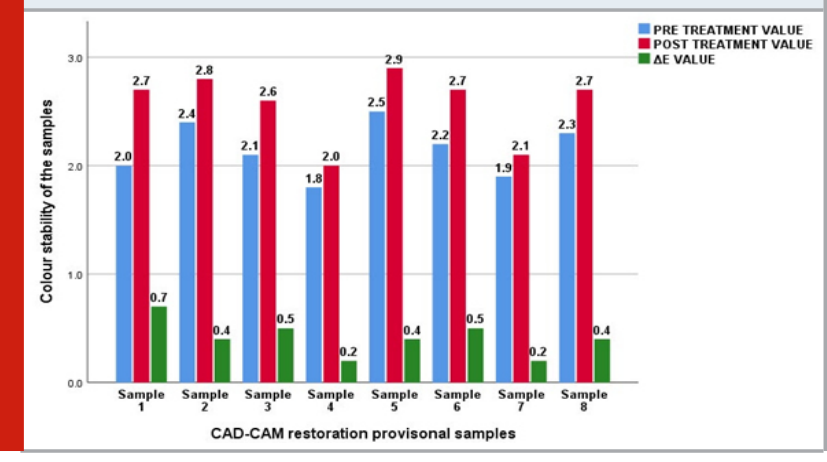

\section{DISCUSSION}

In long term provisional restorations especially in the anterior region, aesthetics is the main concern. To obtain optimal aesthetics, size, shape, colour of the restoration is at-most important. Size and shape of the restorations are in the hands of the dental technicians. But colour and colour stability is one of the major issues in anterior restorations. The colour stability of the restorations can be affected by several factors like surface roughness, absorption of fluids, accumulation of stains, dissolution, erosion by beverages, and degradation of the material(Goiato et al., 2013; Moon, Powers and Kiat-amnuay, 2014)

Colour assessment can be done either by visual examination using shade guides or by using spectrophotometry. This visual examination is subjective to physiological and psychological factors based on the surrounding light. Spectrometry eliminates the subjective evaluation and the surrounding light will not affect the true value of colour (Moon, Powers and Kiat-amnuay, 2014), Colour changes in the restoration denotes the ageing or damage to the material used(Waliszewski, 2005; Oguz et al., 2007; Goiato et al., 2010). CAD-CAM blanks have less residual monomer, improved optical properties when compared to conventional heat cured resin(Güth and Dent, 2012; Güth et al., 2012). In this study, CAD/CAM PMMA resins are compared with a heat cure resin by running it through a brushing simulator. The colour change is determined for all long term provisional restoration as they increase over time. There are intrinsic and extrinsic factors that can cause discolouration of restoration as well(Zuo et al., 2016).

CAD/CAM long term provisional restorations have better colour stability, less porosities, mechanical properties, and fit than the conventional provisional restorations(Yao et al., 2014; Rayyan et al., 2015) The average brushing period of an individual is around 5 minutes per day. In this study, the abrasion is done using a brushing stimulator continuously for 24 hrs. Using the spectrophotometry the colour stability is evaluated after the estimated period of 9 months. The results state that the CAD-CAM provisional has more colour stability than conventional heat-cured provisional even after the usage of 9 months.

\section{CONCLUSION}

The present study concludes that CAD-CAM long term provisional restorations have better colour stability than the conventional heat-cured provisional restorations. CAD-CAM provisional restoration gives better mechanical properties, more aesthetic appeal that ultimately gives a better patient satisfaction.

Conflict of Interest: There were no conflicts of interest as declared by the authors.

\section{ACKNOWLEDGEMENTS}

The authors thank everyone who enabled us to carry out this study.

\section{REFERENCES}

Alp, G., Murat, S. and Yilmaz, B. (2019) 'Comparison of Flexural Strength of Different CAD/CAM PMMA-Based Polymers', Journal of Prosthodontics, pp. e491-e495. doi: 10.1111/jopr.12755.

Anbu, R. T. et al. (2019) 'Comparison of the Efficacy of Three Different Bone Regeneration Materials: An 
Animal Study', European journal of dentistry, 13(1), pp. 22-28.

Ariga, P. et al. (2018) 'Determination of Correlation of Width of Maxillary Anterior Teeth using Extraoral and Intraoral Factors in Indian Population: A Systematic Review', World Journal of Dentistry, 9(1), pp. 68-75. Ashok, V. and Ganapathy, D. (2019) 'A geometrical method to classify face forms', Journal of oral biology and craniofacial research, 9(3), pp. 232-235.

Berger, J. C. et al. (2006) 'Surface Roughness of Denture Base Acrylic Resins After Processing and After Polishing, Journal of Prosthodontics, pp. 180-186. doi: 10.1111/j.1532-849x.2006.00098.x.

Choi, J. E. et al. (2018) 'Adhesive evaluation of three types of resilient denture liners bonded to heatpolymerized, autopolymerized, or CAD-CAM acrylic resin denture bases', The Journal of Prosthetic Dentistry, pp. 699-705. doi: 10.1016/j.prosdent.2018.01.032.

Duraisamy, R. et al. (2019) ‘Compatibility of Nonoriginal Abutments With Implants: Evaluation of Microgap at the Implant-Abutment Interface, With Original and Nonoriginal Abutments', Implant dentistry, 28(3), pp. 289-295.

Evaluation of Corrosive Behavior of Four Nickelchromium Alloys in Artificial Saliva by Cyclic Polarization Test:An in vitro Study' (2017) World Journal of Dentistry, 8(6), pp. 477-482.

Ganapathy, D. M., Kannan, A. and Venugopalan, S. (2017) 'Effect of Coated Surfaces influencing Screw Loosening in Implants: A Systematic Review and Meta-analysis', World Journal of Dentistry, 8(6), pp. 496-502.

Goiato, M. C. et al. (2010) 'Effect of accelerated aging on the microhardness and color stability of flexible resins for dentures', Brazilian Oral Research, pp. 114-119. doi: 10.1590/s1806-83242010000100019.

Goiato, M. C. et al. (2013) 'Effect of different solutions on color stability of acrylic resin-based dentures', Brazilian Oral Research, pp. 1-7. doi: 10.1590/s180683242013005000033.

Gungor, H., Gundogdu, M. and Duymus, Z. Y. (2014) 'Investigation of the effect of different polishing techniques on the surface roughness of denture base and repair materials', The Journal of Prosthetic Dentistry, pp. 1271-1277. doi: 10.1016/j.prosdent.2014.03.023.

Gupta, P., Ariga, P. and Deogade, S. C. (2018) 'Effect of Monopoly-coating Agent on the Surface Roughness of a Tissue Conditioner Subjected to Cleansing and Disinfection: A Contact Profilometric Study', Contemporary clinical dentistry, 9(Suppl 1), pp. S122S126.

Güth, J. F. et al. (2012) 'Enhancing the predictability of complex rehabilitation with a removable CAD/CAM- fabricated long-term provisional prosthesis: A clinical report', The Journal of Prosthetic Dentistry, pp. 1-6. doi: 10.1016/s0022-3913(11)00171-5.

Güth, J.-F. and Dent, M. (2012) 'CAD/CAM-generated high-density polymer restorations for the pretreatment of complex cases: a case report', Quintessence international . researchgate.net, 43, pp. 457-467.

Heydecke, G. et al. (2003) 'Oral and general healthrelated quality of life with conventional and implant dentures', Community Dentistry and Oral Epidemiology, pp. 161-168. doi: 10.1034/j.1600-0528.2003.00029.x. Hong, G. et al. (2009) 'Influence of denture cleansers on the color stability of three types of denture base acrylic resin', The Journal of Prosthetic Dentistry, pp. 205-213. doi: 10.1016/s0022-3913(09)60032-9.

Jain, A. R. (2017a) 'Clinical and Functional Outcomes of Implant Prostheses in Fibula Free Flaps', World Journal of Dentistry, 8(3), pp. 171-176.

Jain, A. R. (2017b) 'Prevalence of Partial Edentulousness and Treatment needs in Rural Population of South India', World Journal of Dentistry, 8(3), pp. 213-217.

Moon, A., Powers, J. M. and Kiat-amnuay, S. (2014) 'Color Stability of Denture Teeth and Acrylic Base Resin Subjected Daily to Various Consumer Cleansers', Journal of Esthetic and Restorative Dentistry, pp. 247-255. doi: 10.1111/jerd.12109.

van Noort, R. (2012) 'The future of dental devices is digital', Dental Materials, pp. 3-12. doi: 10.1016/j. dental.2011.10.014.

Oguz, S. et al. (2007) 'Color Change Evaluation of Denture Soft Lining Materials in Coffee and Tea', Dental Materials Journal, pp. 209-216. doi: 10.4012/ dmj.26.209.

Palaskar, J., Mittal, S. and Singh, S. (2013) 'Comparative evaluation of surface porosities in conventional heat polymerized acrylic resin cured by water bath and microwave energy with microwavable acrylic resin cured by microwave energy', Contemporary Clinical Dentistry, p. 147. doi: 10.4103/0976-237x.114844.

Ranganathan, H., Ganapathy, D. M. and Jain, A. R. (2017) 'Cervical and Incisal Marginal Discrepancy in Ceramic Laminate Veneering Materials: A SEM Analysis', Contemporary clinical dentistry, 8(2), pp. 272-278.

Rayyan, M. M. et al. (2015) 'Comparison of interim restorations fabricated by CAD/CAM with those fabricated manually', The Journal of Prosthetic Dentistry, pp. 414-419. doi: 10.1016/j.prosdent.2015.03.007.

Sahin, 0. et al. (2016) 'Effect of surface sealant agents on the surface roughness and color stability of denture base materials', The Journal of Prosthetic Dentistry, pp. 610-616. doi: 10.1016/j.prosdent.2016.03.007.

Sepúlveda-Navarro, W. F. et al. (2011) 'Color Stability 
of Resins and Nylon as Denture Base Material in Beverages', Journal of Prosthodontics, pp. 632-638. doi: 10.1111/j.1532-849x.2011.00791.x.

Tuna, E. B. et al. (2013) 'Influence of Acrylic Resin Polymerization Methods on Residual Monomer Release', The Journal of Contemporary Dental Practice, pp. 259-264. doi: 10.5005/jp-journals-10024-1310.

Varghese, S. S., Ramesh, A. and Veeraiyan, D. N. (2019) 'Blended Module-Based Teaching in Biostatistics and Research Methodology: A Retrospective Study with Postgraduate Dental Students', Journal of dental education, 83(4), pp. 445-450.

Waliszewski, M. (2005) 'Restoring dentate appearance: A literature review for modern complete denture esthetics', The Journal of Prosthetic Dentistry, pp. 386-394. doi: 10.1016/j.prosdent.2005.01.004.

Yao, J. et al. (2014) 'Comparison of the flexural strength and marginal accuracy of traditional and CAD/CAM interim materials before and after thermal cycling, The Journal of Prosthetic Dentistry, pp. 649-657. doi: 10.1016/j.prosdent.2014.01.012.

Zuo, W. et al. (2016) 'Effects of organic-inorganic hybrid coating on the color stability of denture base resins', The Journal of Prosthetic Dentistry, pp. 103-108. doi: 10.1016/j.prosdent.2015.07.008. 